\title{
"Take-Away" My Childhood: The Second-Generation British Chinese in the Catering Trade
}

\author{
Yun-Hua Hsiao ${ }^{1}$ \\ National Changhua University of Education, Taiwan
}

\begin{abstract}
The British Chinese have long been under-studied and thus, barely understood. Moreover, as the catering trade is an important industry of the British Chinese, those who work in this business are often the target of assault for they need to face people from the outer world, including the unfriendly and even aggressive ones. This paper then focuses on the British Chinese subjects who work in the catering trade, with special attention to the second-generation British Chinese children who are asked to "help out" to facilitate the operation of the business. In their writings, these young people depict their parents' toiling labor and vent their anger on racism and seclusion from social life. Literary productions about or by the second/third generation British Chinese are sparse and dispersed. Based the available pieces created by the second/third-generation British Chinese, this paper aims to examine their struggles working at family-run catering businesses from Miri Song's sociological perspectives.
\end{abstract}

Keywords: British Chinese, catering trade, help out, second-generation.

\section{Introduction}

The contemporary world in 2020 is mostly immobilized under the COVID-19 pandemic. However, before the attack of this coronavirus, World Migration Report 2020, published by the International Organization for Migration of the United Nations (2019), had declared that up until 2019, the number of international migrants had reached 272 million, which was $3.5 \%$ of the global population (p. 3). The Chinese diaspora is among the phenomenon of global migration, and according to the Overseas Community Affairs Council in the Republic of China (OCAC, 2020), the sum of Chinese migrants globally was 49.21 million in 2019. That is to say, international Chinese migrants occupied $18 \%$ of global population of migrants. This significant proportion explains a wide dispersal of the overseas Chinese, but it does not necessarily entail the visibility of the ethnic Chinese in the countries that accommodate them. Even worse is that since the ethnic Chinese are closely related to China, the country which is generally believed to be the origin of the current COVID-19 pandemic, they have become the target of racist assaults. Sinophobia and racism against the Chinese began to spread globally with the outbreak of COVID-19; and hate crime against the Chinese have been reported worldwide. For example, Lovett (2020) noted that cases of hate crime against the Chinese during the pandemic has risen for three times in the United Kingdom, compared to the number of offences occurring in the same months of previous two years.

In the figures presented by the OCAC (2020), subsequent to the continents of Asia and America, Europe hosts a large number of Chinese migrants-2,300,000 in total. According to the Office for National Statistics in the United Kingdom (2011), the British Chinese population reached

${ }^{1}$ Correspondent E-mail: yhua@cc.ncue.edu.tw 
451,500 in England and Wales (p. 2), and this number alone was almost 20\% of all the Chinese migrants in Europe. Moreover, the sociologist Miri Song (2003) asserted that the British Chinese were believed to compose "the third largest ethnic community" in Britain, next to the British subjects of Afro-Caribbean and South Asian origin (p. 99). The Office for National Statistics (2013) pointed out that the Chinese held $0.7 \%$ of the British population in England and Wales in the 2011 census (p. 7), implying that Chinese faces are a common sight in British society. However, even though the Chinese migrants in Britain occupy a significant proportion in the European map of international migration, they have long been under-studied and thus, barely understood. While Afro-Caribbean and South Asian British people ally themselves to "blackness" and request their rights, the Chinese people are often left out and remain silent. The invisibility, if not "secrecy," of the British Chinese renders this minority group alienated from the mainstream society and becomes an easy target for racism. Therefore, it is important to disclose this community to the general public so that racial hate towards the British Chinese may be alleviated, especially during a time when hate crime against them is severe.

Recently, research interest in this ethic group starts to sprout, and studies about the British Chinese include the leisure of British Chinese communities amidst COVID-19 pandemic (Pang, 2020a), the educational success of British Chinese pupils (Francis et al., 2017), mental health resulted from British Chinese cultural impact (Tek \& Lek, 2018), and children of Chinese origin being adopted by and growing up in British families (Grant \& Rushton, 2018). Moreover, Lam and Tran (2017) argued that "little research has explored the ethnic cognition and effect of ethnic Chinese children from Britain and Europe, contrasting the established literature from North America" (p. 135); Knox (2019) proposed that television representations of British Chinese identities have been long neglected; Pang (2020b) also identified the lack of study in the field of British Chinese physicality. Similarly, in the field of literature, little research devotes to the discussion of writings by and about the British Chinese. Literary discussions about the Chinese in Britain are mostly about the author Timothy Mo. Exceptions are a chapter in Grice's (2002) book about women's writing of Communist China and Hsiao's (2014) book-length analysis of women in British Chinese works.

Furthermore, as the catering trade is an important industry of the British Chinese, those who work in this business are often the target of assault for they need to face their neighbors, including the unfriendly and even aggressive ones. Lovett (2020) reported that "a Chinese takeaway owner in Hitchin, Hertfordshire was 'spat at' in the face by a teenage boy who demanded to know if he "had coronavirus"'; the violence in a Chinese takeaway is not a one occurrence. The BBC News (2005) reported about the murder of a Chinese takeaway shop owner thus: "Mi Gao Huang Chen, 41, was battered to death in front of his girlfriend with a spade, tree branch and metal pipes in Scholes, Wigan." The narration continued with the statement indicating that "residents say a gang of teenagers have plagued their community with anti-social behavior." This act of atrocity was not only a result of anti-social behavior but also of racial discrimination. The Guardian journalist Hsiao-Hung Pai (2005), on investigating this crime, argued that the murder is a matter of "antiChinese violence."

In order to enhance the friendliness toward the British Chinese, it is necessary to better understand this ethnic group and their way of survival. This paper then focuses on the British Chinese subjects who work in the catering trade, with special attention to the second-generation British Chinese children who are asked to "help out" to facilitate the operation of the business. In their writings, these young people depict their parents' toiling labor and vent their anger on racism and seclusion from social life. In this way, this paper attempts to present to the public the lives of the British Chinese, not as a successful case of "model minority" but as human beings who have to 
face racial, cultural and familial confrontations, to evoke empathy and friendliness towards this minority community. The British Chinese need be understood as individuals who strive to survive in a country where they are viewed as outsiders; they deserve respect for their courage and strength to endure hardship, instead of becoming targets of racism.

Literary works about or by the second or subsequent generation British Chinese are sparse and dispersed. It seems that besides Timothy Mo's works, only one memoir, Sweet Mandarin: The Courageous True Story of Three Generations of Chinese Women and Their Journey from East to West by Helen Tse ${ }^{2}$ (2007), and three anthologies Exploring Our Chinese Identity (Lacy et al., 1992), Another Province: New Chinese Writing from London (Lim \& Yan, 1994), and Dim Sum (Little Pieces of Heart): British Chinese Short Stories (G. Chan, 1997) are relevant book-length productions so far. Based on the pieces created by the second/third-generation British Chinese, this paper aims to examine their lives working at family-run catering businesses from Miri Song's sociological perspectives. Through the exploration of the British Chinese lives, this research then seeks to foster neighborliness toward the British Chinese, who are undoubtedly members of the British society; in their biographical works, the British Chinese become real-life individuals, who experience hardship and try to make a living in a country where they belong to an ethnic minority. In order to understand British Chinese subjects, it is inevitable to discuss the history of Chinese immigration to Britain, which is believed to be dated in the late eighteenth century.

\section{History of Chinese Immigration to Britain}

The earliest account of any Chinese appearing in Britain was dated 1782, according to David Parker (1999, p.304). In Anthony Shang's research, it was 1851 (1984, p. 8). Sue Baxter and Geoff Raw (1998) also claimed it to be the late eighteenth century, attributing the reason to the shortage of British seamen, who had been "impressed into the Navy for the Napoleonic Wars" (p. 61). Besides a handful of diplomats and students, Chinese people in Britain before the midtwentieth century were predominantly composed of seamen (Benton \& Gomez, 2008, p. 25). China's defeat in the Opium Wars and the opening of trade further contributed to Chinese seamen's arrivals in British ports, especially Liverpool and London. The dock areas of Liverpool and the Limehouse district in London were the first places to accommodate Chinese seamen's settlement. In Limehouse, a Chinatown started to be built from the 1880s (Shang, 1984, p. 9). The existence of Limehouse Chinatown wass explored in the writing of Sax Rohmer, Conan Doyle and Oscar Wilde: Rohmer featured his evil Dr. Fu Manchu, who manipulates his vicious plot in the opium dens in Limehouse; Doyle had Sherlock Holmes pursuing his suspects into the East End docks and the opium dens, which Wilde also portrayed in The Picture of Dorian Gray. It was during the Second World War that many of the buildings in Limehouse were destroyed.

During Chinese people's early settlement in Britain, the animosity towards them was strong. In the early twentieth century, the use of cheap Chinese labor on British ships threatened British seamen's employment; moreover, the image of Chinese sailors as "strike-breakers" at that time aggravated the hostility (Shang, 1984, p. 10). The hatred reached a peak when the 1911 seamen's strike in Cardiff turned into an anti-Chinese riot; Chinese laundries and lodging houses were set ablaze. The Chinese seamen moved away from the dock area after the Second World War; similar to the Chinese in America, those in Britain began their own businesses, mostly laundries. The requirement of little capital to set up a laundry and the low demand for linguistic communication had made Chinese people rush into this profession; in Shang's report on this, there were 800 Chinese laundries in Britain by 1931 (1984, p. 10). A glimpse of the hard work and long working hours of the Chinese laborers in the laundries can be found in The Woman Warrior by the 
Chinese American author Maxine Hong Kingston, who was a Chinese laundry owner's daughter in California during the 1940s. During this early stage of Chinese settlement, nearly all of the Chinese people in Britain were single men and there were few, if any, Chinese women available for marriage; some of these bachelors then married non-Chinese women and produced mixed race children.

The introduction of High Street launderettes and domestic washing machines terminated the development of Chinese laundries in Britain. The catering trade then substituted for the laundry business and became the main occupation for the Chinese people thereafter; most of the secondwave Chinese immigrants arriving in Britain in the 1950s worked at restaurants and takeaways. With the advent of global fast food chains, according to Song (1995), "the dominance of restaurants in the ethnic catering industry receded in the late 1960s and early 1970s" (p. 285). As many Chinese restaurants closed down, takeaways rapidly spread. Takeaways, just like laundries, require little start-up capital and thus especially attracted Chinese people. In addition, Benton and Gomez (2008) pointed out that due to the introduction of selective employment tax in 1966 and then the valueadded tax in 1973, both unfavorable to the profits of restaurants, also contributed to the growth of Chinese takeaways (pp. 122-23). Shang (1984) suggested that there are two kinds of takeaways in Britain: one is "Chop Suey" and the other "Chinese chippy" (p. 25). Chop Suey houses offer a range of Chinese fast food adapted to Western people's taste and Chinese chippy shops provide "fish and chips" and also other Chinese fast-food. Both of them present a sense of hybridity by mixing the tastes of Chinese and Western people.

Song (1995) had confirmed that "the majority of the Chinese in Britain are from the New Territories, the rural part of Hong Kong" (p. 285), and the 1986 report of the Home Affairs Committee asserted that ninety percent of British Chinese people worked in the catering businesses, and around $60 \%$ of them were engaged in small family-run businesses (p. 6) while Clark \& Drinkwater (2006) suggested that 75\% of "male Chinese entrepreneurs worked in the sector [of Distribution, Hotels and Catering] in 1991" (p. 9). The 1950s newcomers were primarily men from rural Hong Kong; due to the competition for cheap labor provided by the refugees from Communist China and low-priced rice from Mainland China and Southeast Asia, rural Hong Kong farmers were forced to leave their homeland in order to earn a living. The colonial link between Britain and Hong Kong had offered an ideal destination for these Chinese farmers, whose arrival brought a tide of chain migration, in which their relatives also came to join them in Britain. After these men's settlement in a new country, their dependents, emigrated as well. The separation between the male emigrants and their dependents usually traversed several years; hence, in Exploring Our Chinese Identity, Wai-ling Tse (1992) expressed her happiness of meeting her father for the first time in her life since he left soon after she was born: "I was overwhelmed with joy to see him" (p. 52).

Most of the second-generation British Chinese people nowadays are descendants of the 1950s Chinese immigrants. The seamen saw themselves as "sojourners," as Shang (1984) claimed, who wished to return to China soon, instead of settling down in Britain (p. 10); hence, the second generation British Chinese produced by them were few. The limitation on immigration also prevented the production of the second generation: the 1914 Aliens Restriction Act forbade the movement of aliens during the wartime; this condition was further extended into the peacetime in 1919 (Shang, 1984, p. 10). The recession of the shipping industry in the 1920s and 1930s saw a further decline in the Chinese population in Britain. Therefore, it can be presumed that the secondgeneration British Chinese population was small before the migration in the 1950s.

Unlike the seamen sojourners, the 1950s emigrants came to settle down, which was proven by the development of Chinese associations and societies in Britain. A significant proportion of second-generation Chinese British individuals, therefore, have parents from Hong Kong. A more 
recent wave of Hong Kong people's migration resulted from their awareness of future plans for Hong Kong to revert to China in 1997. The 1997 handover of Hong Kong to Chinese control caused anxiety among the people in Hong Kong, especially during a time when the memory of the 1989 Tiananmen Massacre was still strong. Kwan's (1997) “A Question of Debt" told a story about a fake marriage between a British man and a Hong Kong girl, who wishes to acquire British residency before 1997. In fact, the 1990 British Nationality (Hong Kong) Act had authorized the granting of citizenship up to 50,000 Hong Kong families. Besides Hong Kong, other British citizens of Chinese descent chiefly originate from Commonwealth countries such as Singapore, Malaysia or even nations in the Caribbean. In the 1991 British Census, the overall Chinese British population is young, mainly falling in the range of twenty to forty-five years old. This explains partially why there is a current lack of writing created by second-generation British Chinese people: before adulthood, a large number of them were confined to the family-run businesses, predominantly Chinese takeaways, and as adults, they endeavor to obtain jobs outside the catering industry so that they will be able to break from this labor-intensive profession.

Considering the close link between the second-generation British Chinese and the catering industry, this paper will focus on child labor in Chinese takeaways. This often unpaid child labor is usually under-studied and overlooked; the most prominent analysis about the concept of "helping out" is Miri Song's sociologist study. Song studied the labor participation of young Chinese people in Britain at takeaways in her works published mainly in the 1990s, and she argued that "children's labor in ethnic businesses has tended to be "invisible" (2001, p. 56). Song's work remains unique nowadays because hardly any scholar has devoted a book-length research to study the topic of Chinese children's labor in takeaways. Therefore, this paper aims at adopting Song's theory to highlight children's labor participation in Chinese takeaways in their literary creations.

\section{Child Labor at the Takeaway and Helping Out}

The operation of a Chinese takeaway shop catering requires considerable labor and long working hours. For example, Lab Ky Mo (1992) in Exploring Our Chinese Identity, declared that his father "practically lived in the kitchen" since the kitchen work was overwhelming and demanded the father to devote most of his time to complete ("Stint," p. 21). Another example is in "Snowdrop" by Mei Chi Chan (1997) in Dim Sum, a Chinese British woman who sees her parents working like machines: "They were not their daytime selves; they became something impersonal, mechanical, and even monstrous....Every ounce of being was consumed in the task of making food. It could not be called "cooking." Cooking sounded too homely" (p. 98). In their daughter's eyes, the immigrant parents are degraded into robotic or monster-like existence. The debasement does not simply influence the immigrants themselves; their children are under impact witnessing the hard work devouring their parents. Chan's negative description of working at the takeaway accorded with Song's (1999) observation: "Working in a Chinese takeaway business in anything but glamorous, given the very long and arduous hours required by such enterprises" (p. 3). Mary Pang's (2003) study also presented a similar observation: "Employment in the Chinese catering trade was hard manual work in unpleasant conditions, with long, unsociable hours" (p. 812). Therefore, it is understandable why the second-generation British Chinese mentioned in the three anthologies find the takeaway occupation distasting, after seeing their parents' toil at this family business.

Besides physical laboring, there is also mental toil in this catering occupation: Chinese takeaways are geographically dispersed due to the business competition for customers; for those who work in small towns, life becomes even more cut off. Shang (1984) thus claimed, "success in 
the takeaway business is sometimes bought at the cost of social isolation, excessively hard work and, in recent years, vulnerability to vandalism and racial harassment" (pp. 26-27). The secondgeneration British Chinese children working at takeaways are positioned in a place where cultures meet and racial confrontations are frequent; therefore, one of the central concerns of secondgeneration British Chinese people is identity, for they have grown up with a sense of cultural differences and are eager to clarify the confusion living in the borderland.

In "Daydream of a Butterfly," Paul Wong (1997b) provided an example of the feeling of having a problematic identity. The protagonist in this story is Anglicized, for he can barely recognize any Chinese words in a Chinese newspaper but is able to read the English newspaper, The Guardian, fluently; however, he also retains part of his Chineseness since he senses himself "reborn and renewed" with Chinese food (p. 12). The story both begins and ends with the protagonist's examination of his reflection in the mirror, implying that he is in a quest of selfhood. Song (2003) argued that due to their Chinese immigrant parents' reliance on their labor at the restaurants and takeaways, and their linguistic ability to mediate daily issues in Britain, these second-generation British Chinese people "tend to experience tensions between two polarized ideals of family and identity - one idealized as Chinese, one as British" (p. 108). This cultural polarity makes them struggle in-between Chineseness and Britishness. Some members of the second generation are afraid of not being British enough: for example, Antonia Lim Bunnin (1992) ascribed her refusal to speak Chinese to the fear of "always speaking Chinese with an English accent" (p. 2); some are worried about their Chineseness being inadequate - many fear both.

The formation of identity is influenced not only by the strangers' gaze but also by parental perspectives. Big Prawn (1992) wrote down her mother's perception of her in the poem "Maaatarrr!": "My mother and I used to have arguments / She used to say I was white, a "gwei". / Now she tells me that I am Chinese, / away from home, born "abroad" (p. 38). ${ }^{3}$ In "Violin Practice," Hi Ching (1997) pointed out a problem which is prevalent in Chinese immigrant families: while the children are westernized, the parents still stick to their cultural origins; therefore, a generational gap occurs and conflicts follow. The parents are disappointed at their children, who deprecate their sacrifice for them, and the children blame the parents for not understanding their needs. The protagonist in "Violin Practice" is tired of parental expectation and confinement while he ponders his physical differences from his white schoolmates. He envies English boys for their freedom from familial restraints and for their physical superiority. This teenager rebels by seemingly obeying his parents but follows his own desires secretly.

The second-generation young people are confused about their identity and highly aware of their differences from their parents, who usually identify themselves with Chinese people. A generation gap thus inevitably exists. Tracy Cheung (1994) analyzed the daughter-mother relationship in her story "A Wayward Girl." From the perspective of an anglicized daughter, Cheung portrayed the confrontation between the two generations while trying to examine the issue of identity. The narrator assumes that her Hong Kong mother is unable to understand her because she speaks "a Cantonese mingled with English, with a South London accent" (p. 159); she remains in confusion about her selfhood at the end of the story. D.K.Y. Lee (1997) provided another example of generational gap in "Game Boy." Set in a Chinese takeaway shop, the story begins with the labor and hardship of working there. Later, a father-son argument is triggered by a letter from the son's school, informing the parents of his truancy. While the father accuses the son of ungratefulness for his labor and sacrifice, the son reveals his pain of being discriminated against by his white peers and being unable to have a social life.

In addition to confusion and stress inside their minds and within the family, the secondgeneration British Chinese have to face the pressure and even violence from the outside world. The 
second-generation British Chinese are sensitive to racial differences between them and other British citizens of non-Chinese ancestry. Most of the racial encounters in the three anthologies selected for discussion are unpleasant experiences: dealing with the inter-race relationships is a common task for these second-generation British Chinese people. Paul Wong's (1997b) story "Uproar" depicted a Chinese British boy being racially bullied. Lili Man (1992) talked about the racial gaze in her poem "Not quite Chinese"; while being aware of how others perceive her, she is clear of who she is. The author who named herself ISCN (1992) told of a shocking event, which occurred when she was eight years old: she was nearly strangled by a classmate because of her ethnicity. Receiving no help from passer-by schoolmates, no comfort from the teachers, and even no support from her family, the girl was seriously hurt and felt "cut like a double-edged sword" (p. 27). She has not healed this wound yet and still demands a reason for her pain.

In the encounters with other British people, members of the second generation recognize the stereotypes forced upon them. Paul Wong (1992) presented Western images of Chinese people his poem "The Great Wall" with stereotypes of the delicate and docile China Doll, the physically weak but intelligent yellow boy who eats strange food, sexually-inferior Oriental men, the evil Fu Manchu, and the Kung-Fu hero Bruce Lee. Being influenced by the stereotypes, British Chinese people shoulder a sense of inferiority. The actor David Yip (1990) thus commented:

The stereotyped image of the Chinese haunts each successive generation, the result of the historic obsession with secrecy and mistrust of anything outside their own community and culture. This pattern of mistrust and exclusion breeds ignorant speculation and malicious parody. The art of self-effacement, of giving away as little as possible, of shutting out all who don't belong, is deeply rooted: the $B B C$ [British-Born Chinese] generation are learning this to their cost. (p. $x$ )

This cost is illustrated by the writing of this generation. Lili Man (1992), born in Hong Kong and brought up in London, told of the story of a British Chinese girl's fantasy being transformed into a white blonde overnight in "A Batty Metamorphosis." At the beginning of the story, the narrator considers this transformation will help her solve the problem of her identity; however, she soon discovers that the metamorphosis only aggravates her confusion. Similarly, Tracy Cheung's (1997) "Snapshots of a Girl's Life" in Dim Sum dealt with racial inferiority. The story starts with a British Chinese girl's dissatisfaction with her appearance; this protagonist, who is in her puberty, first feels inferior to her Western peers but later acquires confidence through the friendship with a black British girl. Pui Fan Lee (1994) discussed the experience of growing-up as a British-born Chinese girl. Being ashamed of carrying Chinese descent and being insulted for her Chineseness, which the protagonist refuses to accept, she dreamed of becoming white.

Yip's remark can also be exemplified by Pang's (2003) research of the second-generation British Chinese. The researcher pointed out that in career pursuits, the "young Chinese adults in Britain" are constrained by "structural factors" like racism (p. 819). Pang further proposed "a bimodal distribution," suggesting that

they [the second-generation British Chinese] aimed to occupy positions at the top end of the British labor market or alternatively, failing that, they preferred to remain within the social and economic security provided by the Chinese catering industry, at the opposite end of the 


\section{labor market, rather than face the anticipated discrimination in the middle levels of the labor market. (p. 819)}

The catering trade ensures the ethnic Chinese a sense of security for they are able to group with one another and work against discrimination together; however, the stereotype about the British Chinese grows stronger. Wong (1997a) wrote about stereotypes imposed on people of Chinese origin. The protagonist is then reminded of his mother's advice: "You have to be twice as good as anyone else to make a success of yourself in this foreign land. People will always judge you by the way you look" (pp. 9-10). For second-generation British Chinese children working at the takeaways, the racial gaze is common as interacting with customers is a daily essentiality.

Song (1995) claimed that children working at takeaways feel "ambivalent" about this work: on the one hand, they receive a sense of achievement via the work and benefit from the learning of interpersonal relationships through interaction with their customers; on the other, they have to experience racism, violence, stress from work, and even guilt if they refuse to "help out" in the family businesses (p. 293). For instance, Lab Ky Mo (1992b) expressed his feeling of a "guilty conscience," seeing his father's hard work and his own lack of contribution to the family-owned takeaway (p. 21). According to Song (1999), "the availability of family labor has tended to be treated as an unquestioned given" (p. 2). The work allocation is usually determined by the parents and not discussed between and family members since the children are "subject to a kind of biding and unspoken contract to help out" (p. 74); the children, even if they feel reluctant to work at takeaways, try to share the workload for "children felt that it would be wrong not to work, when their parents had to work very long and arduous hours in their business" (p. 76).

The children are made to work, but violence is a possible matter that they may encounter. Pui Fan Lee (1994) experienced the murder of a classmate's father, right in her parents' takeaway where she also worked, and was too frightened to tell the police who the murderer was. No matter how terrified the narrator was, nevertheless, she could not close the shop: "Business comes first. No time for emotions" (p. 187). Similarly, in Lee's (1997) story "Game Boy," during a fierce father-son argument, the daughter, Tina, cuts in and ends the story with the matter of fact that "it's time to open [the takeaway]" (p. 67). The children at the ethnic family business are able to recognize that the takeaway is the sole economic source for the family and essential for the familial survival. Working at the takeaways has forced members of the second generation to be prematurely adult. In the narratives in the three collections of British Chinese writing, however, none of them includes positive opinions about the takeaway work. Every protagonist working at a takeaway, in the collected works, wishes to avoid this labor. Lee's "Game Boy" desires a "normal" life, in which he is able to relish the public and private divide: the children born to Chinese takeaway owners are literally "integrated" into this business; they grow up in the shops, and their rooms are above the takeaways.

In Timothy Mo's (1982/1999) novel Sour Sweet, the narrator calls the takeaway the main characters" "home" and "shop" simultaneously (p. 95), and the child Man Kee has to do his homework "at the counter" (p. 282). Aged five, Man Kee starts to provide "convenient help" in the take away (p. 201), accepting cash from the customers and giving back changes. Song (1999) thus claimed, "Chinese take-away businesses are small, labor-intensive enterprises which are conductive to the participation of children, especially since these families' home and work lives are largely intertwined" (p. 57). In Chinese takeaways, the "public" and "private" spheres overlap because the shop is usually where the home is located; the children then naturally accept their roles as helpers (Song, 1995, p. 294). For the children working at takeaways, their lives are "very structured by shop hours" (Song, 1999, p. 60) and "loss of childhood" is a common experience 
shared between them (p. 61). Unlike their peers, second-generation British Chinese children at takeaways need to spend their childhood helping their parents manage the family business, which requires considerable labor and long working time.

Being their parents' translators and laborers, the children usually have to relinquish many leisure activities and their social lives. Therefore, Pui Fan Lee (1994) "hated the Shop. The Takeaway. Or as the locals called it, "The Chinky"' (p. 185). She yearned to be one of the girls who sat "outside" of the takeaway, instead of staying "inside" serving at the counter. The inside/outside divide separates children working at ethnic family businesses and confines the children from carefree childhood. Moreover, the second-generation labor at Chinese takeaways is commonly referred to as "helping out," instead of "working," and is an informal kind of "social relations of production"; it is regarded as a kind of "home ethic" in these British Chinese families. Since the business is the only source of income, helping maintain it becomes an obligation for every member of the family. Song (1995) asserted that "helping out" is "an affirmation of Chinese cultural identity" for it presents a common experience sharing by second-generation British Chinese children (p. 294). Nevertheless, while acknowledging the child labor at ethnic family business consolidates cultural collectivity, I argue that "helping out" also implies a possibility of driving the second generation away from their Chineseness into assimilation into British society since the intensive labor, parental control and direct cultural confrontations from the customers may cause a distaste for being Chinese.

\section{Conclusion}

It may seem, to the outside viewers of the children working in Chinese takeaways, that "Chinese parents are rather ruthless and hard-hearted in their manipulation of children's labor" (Song, 1999, p. 3). For example, Susan Baxter (1988) stated that "The ethnic take-away family business is merely another locus for the continued oppression and exploitation of the Chinese and for Chinese women and children particular, generating on the whole, low levels of profit" (p. 122). However, it should be noted again that the lives of these children are integrated into the family businesses; Song (1999) had argued that the general negativity toward children's labor at Chinese takeaways is too simplistic (p. 4).

First of all, the reasons behind children's labor in Chinese takeaways should be considered. Song (1999) commented that “Children's labor cannot be understood solely or even predominantly in terms of financial considerations" and

\section{Children's roles as translators and mediators could not easily be replaced by employees, because some parents had to rely upon their children for English language assistance and guidance in almost every facet of their lives. (p. 69)}

Many Chinese immigrants in Britain adopt takeaway as their means of survival due to the low start-up capital and better pay. Nevertheless, the daily face-to-face interaction between the immigrants and their customers are likely to create problems, one among them being language and cultural barrier. For the parent-immigrants, their children offer useful assistance to adapt to an unfamiliar society: "Ethnic businesses not only provide a livelihood, but they actually constitute an entire way of life for families who have to adjust to a new life in the aftermath of immigration" (Song, 1999, p. 15). Song affirmed that children in family-run ethnic businesses contribute significantly to the "successful social and economic adaptation of their families" (p. 57). 
Parents and children in Chinese takeaways "reply upon each other for emotional support and ongoing adaptation to new surroundings" (Song, 1999, p. 46). The parents foster the children, and the children, with their knowledge of the English language and culture, help their parents to adapt to a new environment in their host country. The relationship between these family members suggests not only responsibility but "mutual support" and in Song's (1999) studies, the secondgeneration British Chinese people who work in takeaways regard "their contracts in terms of familial interdependence, rather than just having to work for one's parents" ( $p$. 79, original emphasis). The "interdependence" indicates both the financial and emotional needs of both sides, parents and children alike. Moreover, there is "collective sense of responsibility for survival" with the family, derived from "material survival pressures" and "racism" (Song, 1999, p. 76). Sharing the responsivities of operating a family business leads to "close physical proximity" between the family members (James, 2019; Song, 1999). The closer and family unity resulting from the hardships and endeavor for survival can be found in Helen Tse's Sweet Mandarin (2008), which narrates the life stories of working at Chinese catering businesses through three generations.

Owing to the adversity that they encounter, children working at Chinese takeaways are made strong through the constant confrontation with their customers. Siu Won $\mathrm{Ng}$ (1992) expressed her anger about racist and sexist acts which she has to face working at a takeaway counter. Even when being humiliated by a male customer, $\mathrm{Ng}$ keeps her confidence in being a Chinese British woman and is able to discern the man's failed attempt at establishing his manhood through verbal violence:

you were showing off - weren't you in front of your bunch of "mates" but nobody else did smirk apart from your pinky sour face radiating racial hate to make you feel more manly (p. 29)

Ng's awareness of the bully's failure indicates her strength to survive racial and sexual abuse. Children working at Chinese takeaways may feel their childhood wasted and need to shoulder physical and psychological stress; however, if they are able to over the obstacles, they will be empowered through the challenges and brought closer to their family members. Again, Tse's Sweet Mandarin (2007) offers a fine example of how three generations of British Chinese women survive in their host country; the third-generation Tse sisters even discarded their professional occupations and return to the catering business as a tribute to their family:

We determined that we had to create a restaurant which expressed what we were - British-born Chinese in the twenty-first century - and where we'd come from. We were passionate about the food that was our culture and our family inheritance, and we wanted to do it justice. We wanted people to look at it with fresh eyes and taste it with a fresh palate. (p. 264)

The Tse sisters as adults, after undergoing the helping-out period during their childhood, embrace their cultural roots and proudly proclaim their cultural identity. Working at ethnic family business can be an adversity, for the children have to relinquish their childhood and at a young age, face hardships with their immigrant parents; it may also generate an opportunity for the children to become mature and powerful- the previous sufferings may become the nutrition for future flowering.

One limitation of this study lies in the discussion of the following generations deriving from the second-generation British Chinese. Again, literary creations by the second-generation are few; 
the writing about or by the third generation is even harder to find. It seems that Helen Tse's Sweet Mandarin is the only literary production by the third generation, about which Hsiao (2014) had discussed in her work. Moreover, it should be noted that in Benton and Gomez's (2008) study, the "new immigrants," who arrived in Britain after the late 1970s, possessed diverse backgrounds and many of them are highly educated and more funded than their predecessors (p. 57). The new immigrants are professionals in various economic fields and catering is not the only option for their career planning. The newer second-generation British Chinese are likely to change the British impression of their catering-tainted Chinese neighbors in the future, and hopefully this transformation will activate more dynamic research interest in the long-neglected British Chinese subjects, enhance the understanding of this community and decrease the violence resulting from racial discrimination. COVID-19 is altering human beings' ways of living and limiting people's migration; nevertheless, those who had migrated and their descendants should be respected as individuals who were courageous enough to make other countries their homes. The pandemic has caused numerous tragedies, and human beings have to stop ethnic hatred to prevent more tragedies to come.

\section{Notes}

1. "Help out" is a term that Miri Song adopts to describe the generally un-paid labor demanded by ethnic parents to their children in family-run businesses.

2. Sweet Mandarin, written by the third-generation British Chinese Helen Tse, is discussed in Yun-Hua Hsiao's book Women in British Chinese Writings (2014) and therefore, will not be the focus of this paper.

3. "Gwei" means "ghost" in Chinese.

\section{Funding Details}

This work was supported by the Ministry of Science and Technology, Taiwan, R.O.C. under Grant number 107-2635-H-018-001-.

\section{References}

Baxter, S. (1988). A political economy of the ethnic Chinese catering industry. [Unpublished doctoral dissertation], University of Aston.

Baxter, S. \& Raw, G. (1988). Fast food, fettered work: Chinese women in the ethnic catering industry. In S. Westwood \& P. Bhachu (Eds.), Enterprising women: Ethnicity, economy and gender relations (pp. 58-75). Routledge.

BBC News. (2005, April 29). Shopkeeper killed by teenage gang. BBC. http://news.bbc.co.uk/2/hi/uk_news/england/manchester/4496359.stm

Benton, G., \& Gomez, E. T. (2008). The Chinese in Britain: 1800-present: Economy, transnationalism, identity. Palgrave Macmillan.

Bunnin, A. L. (1992). Thoughts on being Chinese. In M. Lacy, L. Man, \& J. Lim (Eds.), Exploring our Chinese identity (pp. 1-3). Lambeth Chinese Community Association.

Chan, G. (Ed.). (1997). Dim sum (little pieces of heart): British Chinese short stories. Crocus .

Chan, M. C. (1997). Snowdrop. In G. Chan (Ed.), Dim sum (pp. 97-99). Crocus.

Cheung, T. (1994). A wayward girl. In J. Lim \& L. Yan (Eds.), Another province (pp. 157-160). Lambeth Chinese Community Association \& SiYu Chinese Times. 
Cheung, T. (1997). Snapshots of a girl's life. In G. Chan (Ed.), Dim sum (pp. 91-96). Crocus . Ching, H. (1997). Violin practice. In G. Chan (Ed.), Dim sum (pp. 47-55). Crocus.

Clark, K., \& Drinkwater, S. (2006, December). Changing patterns of ethnic minority selfemployment in Britain: Evidence from census microdata [Discussion Paper No. 2495]. IZA. file://C:/Users/user/Downloads/SSRN-id955810.pdf

Francis B., Mau, A., \& Archer, L. (2017). Journal of Ethnic \& Migration Studies, 43(14), 23312345. https://doi.org/10.1080/1369183X.2017.1315852

Grant, M., \& Rushton, A. (2018). Further analysis of the British Chinese Adoption Study (BCAS): Adult life events and experiences after international adoption. Children and Youth Services Review, 91, 355-363. https://doi.org/10.1016/j.childyouth.2018.06.004

Grice, H. (2002). Negotiating identities: An introduction to Asian American women's writing. Manchester University Press.

Home Affairs Committee. (1986). Chinese community in Britain: The Home Affairs Committee report in context. Runny Trust.

Hsiao, Y. H. (2014). Women in British Chinese writings: Subjectivity, identity, and hybridity. Chartridge Books Oxford.

International Organization for Migration, United Nations. (2019). Chapter 1 Report Overview: Providing Perspective on Migration and Mobility in Increasingly Uncertain Times. In $\begin{array}{lll}\text { World migration } & \text { report } & \end{array}$ https://publications.iom.int/system/files/pdf/wmr_2020_en_chapter1_004.pdf

ISCN. (1992). Friday 20th March 1992. In M. Lacy, L. Man, \& J. Lim (Eds.), Exploring our Chinese identity (pp. 25-27). Lambeth Chinese Community Association.

James, W. Y. (2019). Imprint of Racism: White Adult Males' Transformational Experience from Racial Antipathy to Racial Reconciliation. American Journal of Qualitative Research, 3(1), 93-116. https://doi.org/10.29333/ajqr/5813

Knox, S. (2019). Representations of British Chinese identities and British television drama: Mapping the field. Journal of British cinema and television, 16(2), 125-145. https://doi.org/10.3366/jbctv.2019.0465

Kwan, T. L. (1997). A question of debt. In G. Chan (Ed.), Dim sum (pp. 75-84). Crocus .

Lacy, M., Man, L., \& Lim, J. (Eds.). (1992). Exploring our Chinese identity. Lambeth Chinese Community Association.

Lam,V. L., \& Tran, D. H. (2017). Ethnic cognition and affect of British-Born Chinese children. Journal of Educational and Developmental Psychology, 7(1). http://dx.doi.org/10.5539/jedp.v7n1p135

Lee, D. K. Y. (1997). Game boy. In G. Chan (Ed.), Dim sum (pp. 63-67). Crocus .

Lee, P. F. (1994). From Short, fat, ugly and Chinese. In M. Lacy, L. Man, \& J. Lim (Eds.), Another province (pp. 172-192). Lambeth Chinese Community Association \& SiYu Chinese Times.

Lim, J., \& Yan, L. (Eds.). (1994). Another province: New Chinese writing from London. Lambeth Chinese Community Association \& SiYu Chinese Times.

Lovett, S. (2020, May 5). Coronavirus: Hate crime against Chinese people almost triple in UK during pandemic, police data shows. The Independent. https://www.independent.co.uk/news/uk/home-news/coronavirus-uk-hate-crimes-chinesepeople-china-a9499991.html

Man, L. (1992). Not quite Chinese. In M. Lacy, L. Man, \& J. Lim (Eds.), Exploring our Chinese identity (p.16). Lambeth Chinese Community Association.

Mo, L. K. (1992a). Chinas with Belfast accents. In M. Lacy, L. Man, \& J. Lim (Eds.), Exploring our Chinese identity (pp. 18-19). Lambeth Chinese Community Association. 
Mo, L. K. (1992b). I did a stint in my dad's shop for a summer or two. In M. Lacy, L. Man, \& J. Lim (Eds.), Exploring our Chinese identity (pp. 20-21). Lambeth Chinese Community Association.

Mo, L. K. (1992c). Jacky - No, sorry, ain, I mean. In M. Lacy, L. Man, \& J. Lim (Eds.), Exploring our Chinese identity (pp. 17-18). Lambeth Chinese Community Association.

Mo, T. (1999). Sour Sweet. Paddleless. (Original work published 1982)

Ng, S. W. (1992). Fish and chips. In M. Lacy, L. Man, \& J. Lim (Eds.), Exploring our Chinese identity (pp. 28-29). Lambeth Chinese Community Association.

Office for National Statistics, United Kingdom. (2011, May 18). Population estimates by ethnic $\begin{array}{ll}\text { group 2002-2009. } & \end{array}$ file:///C:/Users/user/Downloads/populationestimatesbyethnicgroupstatisticalbulletin_tcm7 7-220265\%20(1).pdf

Office for National Statistics, United Kingdom. (2013, July 25). Comparison of mid-2010 population estimates by ethnic group against the 2011 census. C:IUsersluserlDownloads\comparisonofmid2010peegsagainst2011censusestimatesv2_tcm 77-320363.pdf

Overseas Community Affairs Council, Republic of China. (2020). Number of Overseas Chinese. file:///C:/Users/user/Downloads/file_84251\%20(1).pdf

Pai, H. (2005, May 31). Alarm over surge in anti-Chinese violence. The Guardian. http://www.theguardian.com/uk/2005/may/31/race.world?INTCMP=SRCH

Pang, B. (2020a). Beyond hypervisibility and fear: British Chinese communities' leisure and health-related experiences in the time of coronavirus. Leisure Sciences. https://doi.org/10.1080/01490400.2020.1773991

Pang, B. (2020b). Problematising the (in) visibility of racialized and gendered British Chineseness in youth health and physical cultures. Journal of Sport, Education and Society. https://doi.org/10.1080/13573322.2020.1732338

Pang, M. (2003). Boundaryless careers? The (in-)voluntary (re-)actions of some Chinese in Hong Kong and Britain. International Journal of Human Resource Management, 14(5), 809-820. https://doi.org/10.1080/0958519032000080811

Parker, D. (1999). Britain. In L. Pan (Ed.), The encyclopedia of the Chinese overseas (pp. 304309). Curzon.

Prawn, B. (1992). Maaa- tarrr! In M. Lacy, L. Man, \& J. Lim (Eds.), Exploring our Chinese identity (p. 38). Lambeth Chinese Community Association.

Shang, A. (1984). The Chinese in Britain. Batsford Academic and Educational.

Song, M. (1995). Between "the front" and "the back": Chinese women's work in family businesses. Women's Studies International Forum, 18, 285-98. https://doi.org/10.1016/02775395(95)80073-X

Song, M. (1999). Helping out: Children's labor in ethnic businesses. Temple University Press.

Song, M. (2001) Chinese children's work roles in immigrant adaptation. In P. Mizen, C. Pole, \& A. Bolton (Eds.), Hidden hands: International perspectives on children's work and labour (pp. 55-69). Routledge.

Song, M. (2003). Choosing ethnic identity. Polity.

Tek, Y. Y., \& Lek, E. (2018). Culture and reflexivity: Systemic journeys with a British Chinese family. Journal of Family Therapy, 40(4), 520-536. https://doi.org/10.1111/14676427.12205

Tse, H. (2007). Sweet mandarin: The courageous true story of three generations of Chinese women and their journey from east to west. Thomas Dunne. 
Tse, W. (1992). In M. Lacy, L. Man, \& J. Lim (Eds.), Exploring our Chinese identity (pp. 52-55). Lambeth Chinese Community Association.

Wong, P. (1992). The great wall. In M. Lacy, L. Man, \& J. Lim (Eds.), Exploring our Chinese identity (p. 58-59). Lambeth Chinese Community Association.

Wong, P. (1997a). Daydream of a butterfly. In G. Chan (Ed.), Dim sum (pp. 9-18). Crocus.

Wong, P. (1997b) Uproar. In G.Chan (Ed.), Dim sum (pp. 69-74). Crocus.

Yip, D. (1990). Introduction. In T. Mo (Ed.), Sour sweet (pp. v-x). Paddleless.

\section{Notes on Contributors}

Dr. Yun-Hua Hsiao is an associate professor at the Graduate Institute of Children's English and Department of English at National Changhua University of Education in Taiwan. She received her doctoral degree in English Literature from Newcastle University, UK. Her current research interests are in British Chinese writings, cultural studies, and minority women writers. 